\title{
Erratum to: New "hyphenated" CPC-HPLC-DAD-MS strategy for simultaneous isolation, analysis and identification of phytochemicals: application to xanthones from Garcinia mangostana
}

Thomas Michel $\cdot$ Emilie Destandau $\cdot$ Laëtitia Fougère

Claire Elfakir

Received: 31 October 2012 / Accepted: 31 October 2012 / Published online: 17 November 2012

(C) Springer-Verlag Berlin Heidelberg 2012

\section{Erratum to: Anal Bioanal Chem}

\section{DOI 10.1007/s00216-012-6430-8}

Unfortunately, there was a mistake in Figure 4 of this contribution. Please find the correct Figure 4 below.
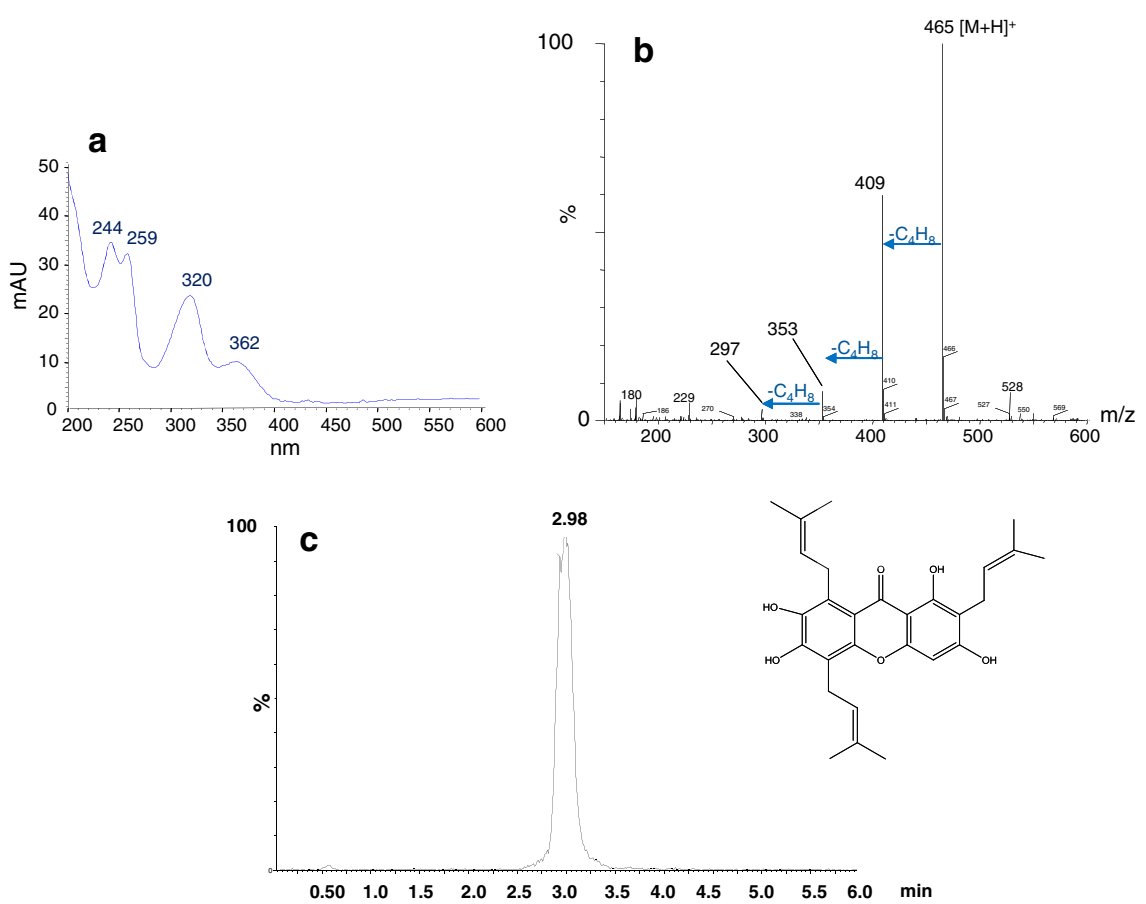

The online version of the original article can be found at http://dx.doi.org/ 10.1007/s00216-012-6430-8.

T. Michel $\cdot$ E. Destandau $(\bowtie) \cdot$ L. Fougère $\cdot$ C. Elfakir Institut de Chimie Organique et Analytique,

Université d'Orléans-CNRS, UMR CNRS 7311,

BP 67059, 45067 Orléans Cedex 2, France

e-mail: emilie.destandau@univ-orleans.fr 